\title{
Incidence and risk factors for mortality after release from prison in Australia: A prospective cohort study
}

\section{Authors}

Simon J. Forsyth ${ }^{1}$

Megan Carroll ${ }^{2}$

Nicholas Lennox ${ }^{3}$

Stuart A. Kinner $2,3,4,5,6$

${ }^{1}$ School of Public Health, University of Queensland

${ }^{2}$ Melbourne School of Population and Global Health, University of Melbourne

${ }^{3}$ Queensland Centre for Intellectual and Developmental Disability, Mater Research Institute-UQ, University of Queensland

${ }^{4}$ Centre for Adolescent Health, Murdoch Children's Research Institute

${ }^{5}$ School of Public Health and Preventive Medicine, Monash University

${ }^{6}$ Griffith Criminology Institute, Griffith University

Running Head: Mortality after release from prison

Word count (abstract): 278 of 300 max.

Word count (main): $3512-12=3500$ of 3500 max.

References: 46

The authors declare they have no disclosures or conflicts of interest. Specifically, the authors have no funding, direct or indirect, or any connection with the tobacco, alcohol, cannabis, pharmaceutical or gaming industries or any body substantially funded by one of these organisations, nor any financial conflict of interest arising from involvement with organisations that seek to provide help with or promote recovery from addiction.

This is the author manuscript accepted for publication and has undergone full peer review but has not been through the copyediting, typesetting, pagination and proofreading process, which may lead to differences between this version and the Version of Record. Please cite this article as doi: $10.1111 /$ add.14106

This article is protected by copyright. All rights reserved. 


\section{Abstract}

Aims: To estimate the incidence and identify risk factors for mortality in adults released from prisons in the state of Queensland, Australia.

Design: Prospective cohort study, linking baseline survey data with a national death register.

Setting: Selected prisons within Queensland, Australia.

Participants: Adults ( $\mathrm{N}=1320)$ recruited in Queensland prisons within 6 weeks of expected release, between August 2008 and July 2010, followed for up to 4.7 years in the community.

Measurements: Participants completed a comprehensive baseline survey covering psychosocial circumstances, physical and mental health, substance use, and health risk behaviours. Clinical data were abstracted from prison medical records and obtained through probabilistic linkage with statebased, community health records. Dates of prison release and reincarceration were obtained from correctional records. Deaths were identified through probabilistic linkage with the National Death Index. Adjusted hazard ratios (AHR) were calculated using proportional hazards regression models. Standardised mortality ratios (SMR) were calculated using the population of Queensland as the reference. General population data were obtained from the Australian Bureau of Statistics.

Findings: The rate of mortality in the cohort was higher than in the age-sex matched general population of Queensland for all causes $(\mathrm{SMR}=4.0,95 \% \mathrm{Cl}=2.9-5.4)$ and drug-related causes $(\mathrm{SMR}=32$, $95 \% \mathrm{Cl}=19-55)$. In a multivariable model, adjusting for age, sex and Indigenous status, factors associated with increased mortality risk included expecting to have average or better funds available on release (AHR=2.9, 99\% $\mathrm{Cl}=1.2-7.1)$, poor mental health (AHR=2.6, 99\% $\mathrm{Cl}=1.1-6.1)$, and selfreported lifetime history of overdose (AHR=2.5, 99\% Cl=1.04-6.2).

Conclusions: People released from prison in Queensland, Australia are at increased risk of death, particularly due to drug-related causes. Those at greatest risk of death are characterised by poor physical and mental health and a history of risky substance use.

Keywords: Prisoners; Mortality; Substance use disorders; Mental disorders; Prospective studies; Data linkage

Correspondence to: Simon Forsyth, School of Public Health, University of Queensland, Herston Road, Herston, Qld 4006, Australia. E-mail: S.Forsyth@uq.edu.au 


\section{Introduction}

People with a history of incarceration are a high-risk group for mortality, particularly in the period immediately after release from prison. The majority of deaths in this period are preventable and due to drug-related causes, suicide or injury $(1,2)$. A recent meta-analysis of this literature estimated that the rate of death within one year of release from prison was around 20 times higher than in age- and sex-matched peers, although the degree of elevation in risk varied markedly between studies (1). Another meta-analysis found that the risk of drug-related death was between three and eight times higher in the first two weeks post-release than in the subsequent ten weeks (3).

Although it is now well established that people released from prison are at increased risk of death, most studies have relied on retrospective linkage of routinely collected data that typically provide narrow demographic and criminogenic information on those at risk, limiting the capacity to inform preventive efforts. One data linkage study of 47,326 ex-prisoners in Sweden linked correctional records and death records with a National Patient Register and found that a history of diagnosed substance use disorder was an independent risk factor for all-cause death (4).

Two studies have used a nested case-control design to study death after release from prison. In these studies, correctional and mortality records are linked, then data from prison medical records for identified cases (deaths) and matched controls are abstracted and analysed. In a study of 699 cases and 699 matched controls in the United States, identified risk factors for all-cause mortality included a history of homelessness, injecting drug use, tobacco use, cirrhosis, and use of psychiatric medications before release from custody. Substance use disorder treatment in prison was protective (5). In a similar study of 286 cases and 286 matched controls in Australia, risk factors for external causes of death included use of heroin and other opioids before incarceration, risky drinking before incarceration, use of antidepressants in prison, and having served two or more prison sentences. Being married was protective (6).

A few studies have examined deaths after release from custody prospectively. In a prospective study of 1829 youth detained in Illinois, USA, from 1995 to 1998 and followed for a median of 14.7 years, those at greatest risk of death were male, black or Hispanic, gang members, and had an alcohol use disorder at baseline (7). In a similar prospective study of 515 juvenile justice clients in Australia, surveyed at baseline and followed for a median of 8.9 years, weekly use of opioids, sleeping pills or painkillers, polydrug use and injecting drug use predicted all-cause death (8). Among 382 heroin users in a randomised trial of in-prison methadone treatment in Australia, followed for an average of 4.2 years, 17 died while out of treatment and none died while in treatment (9). Most recently, in a prospective observational study of 12,260 people with an opioid use disorder released from prisons in England, 24 deaths were observed (18 drug-related) within 4 weeks of release; the risk of death was lower in those receiving opioid substitution treatment (OST) at release (10).

These studies suggest that those with a history of poor mental health, risky substance use and social marginalisation are at greatest risk of death after release from custody. However, most studies have been retrospective in design, and have relied exclusively on administrative data which typically 
suffer from crude ascertainment of risk and protective factors, and may be vulnerable to ascertainment bias. As such, the evidence base remains thin and further research, focussing on identification and characterisation of modifiable risk factors, is required to inform targeted prevention. The aim of this study was to identify risk and protective factors for all-cause mortality, in a cohort of adults followed prospectively from prison into the community in the state of Queensland, Australia. A secondary aim was to calculate the all-cause and drug-related mortality rates in the cohort, and compare these with the general population of Queensland.

\section{Methods}

This is a prospective cohort study with data linkage, in which participants completed a baseline survey prior to release from prison, and were followed prospectively until death or censoring. The original study was a randomised controlled trial (RCT) of a case management intervention for adults transitioning from prison to the community in the state of Queensland, Australia. The trial design and outcomes are described in detail elsewhere (11-13). Those eligible for participation were sentenced prisoners within six weeks of expected release from custody who were able to provide informed, written consent. Of those approached and eligible, $80 \%$ consented to participate. The cohort is representative of adults released from prison in Queensland during the study period, on measured demographic and criminal justice variables, except that women were intentionally oversampled (11). All participants from the original RCT were included in the analyses presented here.

Approval for the study was provided by the University of Queensland's Behavioural and Social Sciences Ethical Review Committee, the Queensland Corrective Services (QCS) Research Committee, the Queensland Health Human Research Ethics Committee, and the Australia Institute of Health and Welfare (AlHW) Ethics Committee.

\section{Baseline characteristics}

Baseline interviews took place from August 2008 to July 2010. Interviews were conducted in a private location within the prison, by trained interviewers not affiliated with corrections. The interview covered socio-demographic characteristics, physical and mental health, substance use and health risk behaviours.

Selection of baseline variables for analysis was informed by the literature (14) and included variables that may have a causal relationship with mortality, and those that could be construed as markers for mortality risk. We categorised variables into five broad domains: socio-demographic, criminal justice system exposure, mental health, physical health, and substance use.

Demographic variables included age in years at release, sex, Indigenous status, years of education, and current relationship status. Participants reported whether they had been taken away from their family as a child, any arrangements for stable accommodation after release from prison, whether they had any outstanding debts, available money after release from custody, and whether they had accessed any sort of transitional support in prison. Perceived social support was assessed using the ENRICHD Social Support Inventory (ESSI) (15). Criminal justice system history included juvenile 
detention, prior incarceration as an adult, and number of subsequent incarcerations between interview and censoring.

Physical health-related functioning was assessed using the Physical Component Summary (PCS) score from the Short Form Health Survey version 2 (SF36v2) using Australian population standards (16, 17). Participants also self-reported diagnosis of asthma, diabetes, and heart disease, responding to questions sourced from Australia's National Health Survey (18). Waist to height ratio (WHR) was measured objectively by the interviewer, and was used to classify individuals as overweight or obese using standard cut-offs (19).

Mental health-related functioning was assessed using the Mental Component Summary (MCS) score from the SF36v2. Psychological distress in the past four weeks was measured using the Kessler Psychological Distress scale (K10) (20). We screened for intellectual disability using the Hayes Ability Screening Index (HASI) (21). Participants also indicated whether they were currently suffering from a mental disorder that had been diagnosed by a mental health professional, and whether they had ever attempted suicide.

Risky alcohol use was measured using the Alcohol Use Disorders Identification Test (AUDIT) (22). High risk use of heroin and other opiates, methamphetamine, and cannabis were assessed using the WHO Alcohol, Smoking and Substance Involvement Screening Test (ASSIST) (23). Nicotine dependence was assessed using the Fagerström Test (24). Participants also reported on drug use history, and whether they had ever experienced a drug overdose.

Self-report data were supplemented by a review of prison medical records. We obtained information on current prescribed medications, which were grouped into those acting on the central nervous system (CNS, a proxy for psychiatric medications) and those used primarily to treat physical health conditions (non-CNS medications). We also obtained information on hepatitis $\mathrm{C}$ infection (anti-HCV+) where prison-based test results had been recorded.

We also undertook retrospective, probabilistic linkage (25) with state-based, electronic health records to identify evidence of historical morbidity from 1999 onwards. From hospital records we identified instances of psychiatric hospital admission. From ambulatory alcohol, tobacco and other drug treatment records we created a binary variable reflecting any history of treatment for a substance use problem before incarceration. From a state-wide notifiable diseases register we identified instances of hepatitis $\mathrm{C}$ infection (anti-HCV+), and combined these with prison medical records into a single binary variable reflecting any medically verified record of hepatitis $\mathrm{C}$ infection.

Participant identities were probabilistically linked with mortality data from Australia's National Death Index (NDI). The linkage added up to nine ICD-10 coded causes of death, with dates of death having a possible range of 18 August 2008 to 31 May 2013. There were no deaths in custody reported for the study sample during the study period. Causes of death were not available for deaths occurring in the year 2013.

This article is protected by copyright. All rights reserved. 


\section{Statistical analysis}

We calculated person time starting from the date of the first release after baseline interview, and censored on 31 May 2013 or death, with any time in prison removed from follow-up time at risk.

We calculated the all-cause crude mortality rate (CMR) per 1000 person years during follow-up, and calculated indirectly standardised mortality ratios (SMRs) comparing participants to the 10 year age group and sex matched general population in Queensland $(26,27)$.

To describe the causes of death we categorised ICD codes into groups proposed by Randall et al (28). Due to the low number of deaths, we constructed three overlapping cause of death groups based on previous literature, and then calculated the CMR and SMR for those groups. These groups include (a) unnatural deaths, (b) drug-related deaths, and (c) alcohol and other drug-related deaths (supplementary table S1).

To identify risk and protective factors for death we constructed a series of proportional hazards models to generate hazard ratios for each potential risk factor. The majority of variables were collected in binary form; others were dichotomised using common cut-offs found in the literature, or a variation of means/medians as appropriate (supplementary table S2). Each model was adjusted for Indigenous status, sex and age in decades at release, with the confidence interval reported at the $99 \%$ level to account for the large number of variables tested.

Next, we assessed those variables that were significant $(p<.01)$ that we suspected as being highly associated, and selected the best explanatory covariate using a stepwise approach (supplementary note S5). The remaining significant covariates were then entered into a multivariable model, into which we forced the inclusion of sex and Indigenous status to be consistent with the standard covariates used previously. Records having covariates with missing values were removed from the models.

All analyses were carried out using SAS version 9.4 (29).

\section{Results}

Of the 1325 participants, five were excluded because there was no valid date of release from prison during the follow-up period, leaving 1320 participants for this analysis. Participants contributed from 7 days to 4.7 years of person-time in the community, with a median follow-up of 3.3 years (Q1Q3=2.6-3.9) and total follow-up of 4154 person years in the community (Table 1). There were 706 (53.5\%) participants who returned to prison up to 21 times during the follow-up period, with a total of 784 person years spent in prison during follow-up that were excluded from analysis. At the end of the study follow-up period there were 217 (16.4\%) participants in prison.

INSERT TABLE 1

\section{Mortality}

We observed 42 deaths (3.2\%) during follow-up, giving a crude mortality rate of 10 (95\% $\mathrm{Cl}=7.5-14)$ deaths per 1000 person years. The age and sex adjusted all-cause standardised mortality rate was 
4.0 $(95 \% \mathrm{Cl}=2.9-5.4)$ times higher for ex-prisoners than for the general population of Queensland (Table 2).

\section{INSERT TABLE 2}

There were 4 deaths in 2013 that were not assigned a cause of death at the time of data extraction. Of the 38 participants with known causes of death, 22 included unnatural causes. The mortality rate for unnatural deaths was $5.3(95 \% \mathrm{Cl}=3.5-8.0)$ deaths per 1000 person years, which was 7.3 $(95 \% \mathrm{Cl}=4.8-11)$ times higher than in the general population of Queensland when adjusted for age and sex.

Nineteen deaths were alcohol or other drug-related and of these, 14 were classified as an overdose. Of the overdose deaths, one involved alcohol only, three involved alcohol and other drugs including benzodiazepines and/or an opioid, and the remaining 10 were non-alcohol, opioid-related overdoses, with three of these mixed with a benzodiazepine. The drug-related mortality rate was 3.4 $(95 \% \mathrm{Cl}=2.0-5.7)$ deaths per 1000 person years, which was $32(95 \% \mathrm{Cl}=19-55)$ times higher than in the age-sex matched general population of Queensland. The combined alcohol and other drug-related mortality rate was $4.6(95 \% \mathrm{Cl}=2.9-7.2)$ deaths per 1000 person years, which was $22(95 \% \mathrm{Cl}=14-35)$ times that of the age and sex matched general population of Queensland.

\section{Risk factors for all-cause mortality}

Table 3 presents the hazard of all-cause mortality as a function of selected risk factors, adjusted for age, sex and Indigenous status. We found no association between sex or Indigenous status and death. After adjusting for sex and Indigenous status, each decade of age was associated with a $65 \%$ increase in the hazard of all-cause mortality. We identified five other variables that were significantly associated with mortality, spanning socio-demographic, physical health, mental health and substance use domains.

\section{INSERT TABLE 3}

We examined the significant variables noting pairs that were highly correlated: "History of psychiatric hospitalisation" with "SF36 Mental health summary score", and "Hepatitis C positive" with "Ever overdosed". We used a stepwise removal process (supplementary table S5) to remove the least explanatory variable of each pair, then combined the remaining significant covariates, plus sex and Indigenous status, into a multivariable proportional hazards model to predict all-cause mortality (Table 4). The model yielded four factors that were significantly $(p<.01)$ associated with allcause mortality: age (AHR=1.7 per decade older), expected money on release being average or greater ( $A H R=2.9)$, low mental-health-related functioning ( $A H R=2.6)$, and lifetime history of overdose $(\mathrm{AHR}=2.5)$.

INSERT TABLE 4

This article is protected by copyright. All rights reserved. 


\section{Discussion}

We examined the incidence and risk factors for mortality in a representative cohort of adults followed prospectively from prison into the community in Australia. We observed an all-cause crude mortality rate of 10 deaths per 1,000 person-years, which is similar to that reported in a recent national report on the health of Australia's prisoners (30). We estimated that this rate of death is 4 times greater than in the age-sex matched general population of Queensland; this is consistent with the findings of previous studies within and outside of Australia (1). People released from prison are at dramatically increased risk of death, typically due to preventable causes.

We identified a number of factors that were associated with mortality, across multiple health and social domains. While the leading causes of death were alcohol and other drug-related, the risk factors associated with all-cause mortality also included poor physical and mental health. Two measures of mental health were associated with mortality: history of psychiatric hospitalisation, and poor mental health-related functioning prior to release from prison. Previous data linkage studies have documented an association between history of psychiatric illness and all-cause mortality (4), and between in-prison psychiatric hospitalisation and suicide (31). Our findings, informed by careful assessment of mental health status at the point of release from prison, add to the growing body of international evidence highlighting the vulnerability of people with a history of mental illness as they transition from prison to the community (32). In addition to careful history taking, there is a clear need for routine assessment of mental health status prior to release from prison, and for evidencebased re-entry support for those identified as vulnerable (33).

In our study over $40 \%$ of deaths were substance-related, and the rate of substance-related death was more than 20 times that of age and sex matched community peers. Consistent with evidence that nonfatal overdose increases the risk of subsequent fatal overdose (34), we found that participants who reported a lifetime history of overdose had two and a half times the hazard of death after release from prison. Routine assessment of overdose history at prison reception, and again prior to release, may assist in identifying those at greatest risk of death. People who inject drugs are dramatically over-represented in prison settings, and are at high risk of substance-related morbidity and mortality after release from custody $(35,36)$. Critical, evidence-based preventive measures include opioid substitution treatment (OST) in prison and after release from prison, and provision of naloxone for peer administration at release (37-40). Neither of these measures was available to prisoners in the jurisdiction where this study was conducted (with the exception of a minority of women receiving OST).

Although fewer than one in ten deaths was due to liver disease, in unadjusted analyses we found that hepatitis $\mathrm{C}$ infection was associated with an increased risk of all-cause mortality. One possible explanation for this finding, consistent with the fact that almost half of all deaths were substance related, is that hepatic dysfunction associated with chronic hepatitis $C$ infection slowed drug metabolisation, increasing the risk of overdose (41). However, HCV infection was also strongly associated with injecting drug use in our cohort $(\mathrm{RR}=6.3,95 \% \mathrm{Cl}=4.4-9.0)$ and lifetime overdose 
history ( $\mathrm{RR}=3.3,95 \% \mathrm{Cl}=2.7-4.0)$, suggesting that it may have served as a marker for prolonged or high-risk injecting drug use. The association between injecting drug use and mortality is well documented (42).

In contrast to some previous studies that have found a dose-response relationship between episodes of incarceration and mortality risk (43), none of the criminal justice system factors we examined was independently associated with mortality. Although a study with more statistical power may have produced different results, these findings nevertheless highlight the importance of assessing and responding to the health and social needs of people transitioning from prison to community in order to reduce mortality in this population (44).

Unexpectedly, we found that participants who expected to have access to more money than average on release from prison were at increased risk of death. This finding contrasts with evidence from general population studies, where social disadvantage and relative deprivation are associated with increased mortality risk (45). One possible explanation for this finding is that individuals with more disposable income on release from prison engaged in more extensive and risky substance use after release. Although we have no data to support this hypothesis, previous cohort studies of regular illicit drug users have documented a positive association between income and intensity of drug use (46). This finding will require replication and further exploration in future studies.

Our study is among only a handful internationally to examine mortality outcomes after release from prison using a prospective design. Important strengths include the large, representative sample, rich baseline data obtained from surveys, clinical records and retrospectively linked health data, accounting for subsequent episodes of incarceration, and linkage with a national death register. Although many of our findings are consistent with previous research that has relied on linked administrative data, our rich ascertainment of risk and protective factors provides important confirmation of these associations.

The study had two notable limitations. First, like most studies in this literature, our findings relate to only one jurisdiction. Second, because death is a rare event and our period of follow-up was comparatively short, we identified only a small number of deaths, and had modest statistical power. However, the number of deaths observed in our study is larger than in some previous prospective studies of mortality after release from prison $(9,10)$, and our estimates of both mortality rates and risk factors for death are consistent with previous research.

Future studies linking prison records with not only mortality records but also morbidity data should provide new insights into the health-related trajectories of those who die prematurely after release from prison. Furthermore, with growing adoption of electronic health records in prison settings, future studies may be able to combine the advantages of this study (rich baseline data) with the advantages of population data linkage (power and generalisability). 


\section{Conclusions}

People released from prison are at markedly increased risk of death, particularly due to drug-related causes. Those at greatest risk of death are characterised by social disadvantage, poor physical and mental health, and a history of risky substance use. Given that complex health and social needs are normative among people released from prison in most countries, preventive efforts in custody and after return to the community must be commensurately comprehensive and coordinated, and delivered at a scale proportionate to need.

This article is protected by copyright. All rights reserved. 


\section{Acknowledgments}

The authors wish to thank Queensland Corrective Services for assistance with data collection, and Passports study participants for sharing their stories. Data included in the National Death Index are provided to the AlHW by the Registries of Births, Deaths and Marriages and the National Coronial Information System (managed by the Victorian Department of Justice) and include cause of death coded by the Australian Bureau of Statistics (ABS). The Passports study was funded by National Health and Medical Research Council (NHMRC) Strategic Award APP409966 and NHMRC Project Grant APP1002463. Stuart Kinner is supported by NHMRC Senior Research Fellowship APP1078168. The views expressed herein are solely those of the authors, and in no way reflect the views or policies of Queensland Corrective Services. 


\section{References}

1. Kinner SA, Forsyth S, Williams G. Systematic review of record linkage studies of mortality in ex-prisoners: why (good) methods matter. Addiction. 2013;108(1):38-49.

2. Zlodre J, Fazel S. All-cause and external mortality in released prisoners: systematic review and meta-analysis. Am J Public Health. 2012;102(12):e67-75.

3. Merrall EL, Kariminia A, Binswanger IA, Hobbs MS, Farrell M, Marsden J, et al. Metaanalysis of drug-related deaths soon after release from prison. Addiction. 2010;105(9):154554.

4. Chang Z, Lichtenstein P, Larsson H, Fazel S. Substance use disorders, psychiatric disorders, and mortality after release from prison: a nationwide longitudinal cohort study. Lancet Psychiat. 2015;2(5):422-30.

5. $\quad$ Binswanger IA, Stern MF, Yamashita TE, Mueller SR, Baggett TP, Blatchford PJ.

Clinical risk factors for death after release from prison in Washington State: a nested casecontrol study. Addiction. 2016;111(3):499-510.

6. Spittal MJ, Forsyth S, Borschmann R, Young JT, Kinner SA. Modifiable risk factors for external cause mortality after release from prison: a nested case-control study.

Epidemiology and Psychiatric Sciences. in press.

7. Teplin LA, Jakubowski JA, Abram KM, Olson ND, Stokes ML, Welty LJ. Firearm homicide and other causes of death in delinquents: a 16-year prospective study. Pediatrics. 2014;134(1):63-73.

8. Kinner SA, Degenhardt L, Coffey C, Hearps S, Spittal M, Sawyer S, et al. Substance use and risk of death in young offenders: A prospective data linkage study. Drug and Alcohol Review. 2015;34:46-50.

9. Dolan KA, Shearer J, White B, Zhou J, Kaldor J, Wodak AD. Four-year follow-up of imprisoned male heroin users and methadone treatment: mortality, re-incarceration and hepatitis C infection. Addiction. 2005;100(6):820-8.

10. Marsden J, Stillwell G, Jones H, Cooper A, Eastwood B, Farrell M, et al. Does exposure to opioid substitution treatment in prison reduce the risk of death after release? A national prospective observational study in England. Addiction. 2017;112(8):1408-18.

11. Kinner SA, Lennox N, Williams GW, Carroll M, Quinn B, Boyle F, et al. Randomised controlled trial of a service brokerage intervention for ex-prisoners in Australia.

Contemporary Clinical Trails. 2013;36:198-206.

12. Kinner SA, van Dooren K, Boyle F, Longo M, Lennox N. Development of an intervention to increase health service utilisation in ex-prisoners. Health and Justice. 2014;2(4).

13. Kinner SA, Alati R, Longo M, Spittal M, Boyle F, Williams GN, et al. Low-intensity case management increases contact with primary care in recently released prisoners: A singleblinded, multisite, randomised controlled trial. Journal of Epidemiology \& Community Health. 2016;70:683-8. 
14. Kinner SA, Binswanger IA. Mortality after release from prison. In: Bruinsma GJN, Weisburd DL, editors. Encyclopedia of Criminology and Criminal Justice. Washington DC: Springer; 2013.

15. Mitchell PH, Powell L, Blumenthal J, Norten J, Ironson G, Pitula CR, et al. A Short Social Support Measure for Patients Recovering From Myocardial Infarction: THE ENRICHD SOCIAL SUPPORT INVENTORY. Journal of Cardiopulmonary Rehabilitation and Prevention. 2003;23(6):398-403.

16. Hawthorne G, Osborne R, Sansoni J, Taylor A. The SF-36 Version 2: critical analysis of population weights, scoring algorithms and population norms. Quality of Life Research. 2007;16(4):661-73.

17. Ware JE, Kosinski M, Dewey JE. How to score version 2 of the SF-36 health survey: standard \& acute forms: QualityMetric; 2001.

18. ABS. National Health Survey: Users' Guide 2004-05. Cat. No. 4363.0.55.001.

Canberra: Australian Bureau of Statistics; 2006. Report No.: 3101.0.

19. Dalton M, Cameron AJ, Zimmet PZ, Shaw JE, Jolley D, Dunstan DW, et al. Waist circumference, waist-hip ratio and body mass index and their correlation with cardiovascular disease risk factors in Australian adults. J Intern Med. 2003;254(6):555-63. 20. Kessler RC, Barker PR, Colpe LJ, Epstein JF, Gfroerer JC, Hiripi E, et al. Screening for serious mental illness in the general population. Arch Gen Psychiatry. 2003;60(2):184-9. 21. Hayes S. Hayes Ability Screening Index (HASI) Manual. Faculty of Medicine: University of Sydney; 2000.

22. Babor TF, Higgins-Biddle JC, Saunders JB, Monteiro MG, World Health Organization. Dept. of Mental Health and Substance Dependence. AUDIT : the Alcohol Use Disorders Identification Test : guidelines for use in primary health care. 2nd ed. Geneva: World Health Organization; 2001. 38 p. p.

23. Ali R, Awwad E, Babor TF, Bradley F, Butau T, Farrell M, et al. The alcohol, smoking and substance involvement screening test (ASSIST): development, reliability and feasibility. Addiction. 2002;97(9):1183-94.

24. Heatherton TF, Kozlowski LT, Frecker RC, Fagerstrom K-O. The Fagerstrom Test for Nicotine Dependence: a revision of the Fagerstrom Tolerance Questionnaire. British Journal of Addiction. 1991;86(9):1119-27.

25. Sayers A, Ben-Shlomo Y, Blom AW, Steele F. Probabilistic record linkage. Int J Epidemiol. 2016;45(3):954-64.

26. ABS. Causes of Death in Australia. Cat. No. 3302.0. Canberra: Australian Bureau of Statistics; 2014.

27. ABS. Australian Demographic Statistics. Cat. No. 3101.0. Canberra: Australian Bureau of Statistics; 2015.

28. Randall D, Roxburgh A, Gibson A, Degenhardt L. Mortality among people who use illicit drugs: A toolkit for classifying major causes of death. University Of New South Wales, Centre NDAAR; 2009. Contract No.: Technical Report No. 301. 
29. SAS Institute. The SAS system for Windows version. 9.4 ed. Cary NC: SAS Publishing; 2012.

30. AlHW. The health of Australia's prisoners 2015. Canberra: Australian Institute of Health and Welfare; 2015. Report No.: PHE 207.

31. Karaminia A, Law MG, Butler TG, Levy MH, Corber SP, Kaldor JM, et al. Suicide risk among recently released prisoners in New South Wales, Australia. Medical Journal of Australia. 2007;187(7):387-90.

32. Cutcher Z, Degenhardt L, Alati R, Kinner SA. Poor health and social outcomes for exprisoners with a history of mental disorder: a longitudinal study. Aust N Z Publ Health. 2014;38(5):424-9.

33. Jarrett M, Thornicroft G, Forrester A, Harty M, Senior J, King C, et al. Continuity of care for recently released prisoners with mental illness: a pilot randomised controlled trial testing the feasibility of a Critical Time Intervention. Epidemiol Psychiatr Sci. 2012;21(2):18793.

34. Stoové MA, Dietze PM, Jolley D. Overdose deaths following previous non-fatal heroin overdose: Record linkage of ambulance attendance and death registry data. Drug and Alcohol Review. 2009;28(4):347-52.

35. Winter RJ, Stoove M, Degenhardt L, Hellard ME, Spelman T, Jenkinson R, et al. Incidence and predictors of non-fatal drug overdose after release from prison among people who inject drugs in Queensland, Australia. Drug Alcohol Depend. 2015;153:43-9.

36. Teesson M, Marel C, Darke S, Ross J, Slade T, Burns L, et al. Trajectories of heroin use: 10-11-year findings from the Australian Treatment Outcome Study. Addiction. 2017;112(6):1056-68.

37. Zucker $\mathrm{H}$, Annucci AJ, Stancliff S, Catania H. Overdose prevention for prisoners in New York: a novel program and collaboration. Harm Reduct J. 2015;12(1):51.

38. Degenhardt L, Larney S, Kimber J, Gisev N, Farrell M, Dobbins T, et al. The impact of opioid substitution therapy on mortality post-release from prison: retrospective data linkage study. Addiction. 2014.

39. Wakeman SE, Bowman SE, McKenzie M, Jeronimo A, Rich JD. Preventing death among the recently incarcerated: an argument for naloxone prescription before release. J Addict Dis. 2009;28(2):124-9.

40. WHO. Preventing overdose deaths in the criminal-justice system. Copenhagen: World Health Organisation: WHO Regional Office for Europe; 2014.

41. Warner-Smith M, Darke S, Lynskey M, Hall W. Heroin overdose: causes and consequences. Addiction. 2001;96(8):1113-25.

42. Mathers BM, Degenhardt L, Bucello C, Lemon J, Wiessing L, Hickman M. Mortality among people who inject drugs: a systematic review and meta-analysis. B World Health Organ. 2013;91(2):102-23.

43. Kariminia A, Butler TG, Corben SP, Levy MH, Grant L, Kaldor JM, et al. Extreme causespecific mortality in a cohort of adult prisoners--1988 to 2002: a data-linkage study. Int J Epidemiol. 2006;36(2):310-6. 
44. Kinner SA, Wang EA. The case for improving the health of ex-prisoners. American Journal of Public Health. 2014;104(8):1352-5.

45. Marmot M, Bell R. Fair society, healthy lives. Public Health. 2012;126(Supplement 1):S4-S10.

46. MacDonald Z, Pudney S. Illicit drug use, unemployment, and occupational attainment. J Health Econ. 2000;19(6):1089-115.

This article is protected by copyright. All rights reserved. 
Table 1. Baseline characteristics of participants, according to age at release.

\begin{tabular}{lccc}
\hline Characteristic & $<25$ years & $\geq 25$ years & Total \\
\hline $\mathrm{N}(\%)$ & $331(25.1 \%)$ & $989(74.9 \%)$ & $1320(100 \%)$ \\
Indigenous, N (\%) & $106(32.0 \%)$ & $229(23.2 \%)$ & $335(25.4 \%)$ \\
Male, $\mathrm{N}(\%)$ & $263(79.5 \%)$ & $778(78.7 \%)$ & $1041(78.9 \%)$ \\
Re-imprisonments ${ }^{\mathrm{A}}$, mean (min-max) & $1.0(0-10)$ & $1.3(0-21)$ & $1.2(0-21)$ \\
Person time in community & & & \\
$\quad$ Sum years (range per person) & $950(0.21-4.7)$ & $3,204(0.02-4.7)$ & $4,154(0.02-4.7)$ \\
$\quad$ Median years ${ }^{\mathrm{A}}(\mathrm{IQR})$ & $3.1(2.1-3.7)$ & $3.4(2.7-4.0)$ & $3.3(2.6-3.9)$ \\
Deaths, $\mathrm{N}(\%)$ & $3(1.2 \%)$ & $39(3.6 \%)$ & $42(3.2 \%)$ \\
Crude mortality rate ${ }^{\mathrm{B}}(95 \% \mathrm{Cl})$ & $3.2(1.0-9.8)$ & $12(8.9-17)$ & $10(7.5-14)$ \\
\hline
\end{tabular}

${ }^{A}$ Per participant after index release and prior to end of follow up.

${ }^{\mathrm{B}}$ Crude mortality rate is deaths per 1000 person years. 
Table 2. Crude mortality rates and indirectly standardised mortality ratios for selected causes of death.

\begin{tabular}{lcccc}
\hline & \multicolumn{2}{c}{ Deaths } & $\mathrm{CMR}^{\mathrm{A}}$ & $\mathrm{SMR}^{\mathrm{B}}$ \\
Cause of death & Observed & Expected & $(95 \% \mathrm{Cl})$ & $(95 \% \mathrm{Cl})$ \\
\hline All cause & 42 & 11 & $10(7.5-14)$ & $4.0(2.9-5.4)$ \\
Unnatural & 22 & 3.0 & $5.3(3.5-8.0)$ & $7.3(4.8-11)$ \\
Drug related & 14 & 0.43 & $3.4(2.0-5.7)$ & $32(19-55)$ \\
Alcohol or drug related & 19 & 0.85 & $4.6(2.9-7.2)$ & $22(14-35)$ \\
\hline A Crude mortality rate (CMR) is measured as deaths per 1000 person years. \\
B Standardised mortality ratio (SMR) is standardised by sex and 10 year age group to the Queensland \\
general population.
\end{tabular}

This article is protected by copyright. All rights reserved. 
Table 3. Cox proportional hazards models for all-cause mortality, adjusted for age, sex and Indigenous status.

\begin{tabular}{|c|c|c|c|c|}
\hline Measure & $\mathbf{N}(\%)^{A}$ & Deaths $^{B}$ & $\mathrm{AHR}^{\mathrm{C}}(99 \% \mathrm{Cl})$ & P value \\
\hline \multicolumn{5}{|l|}{ STANDARD COVARIATES $^{D}$} \\
\hline Indigenous & 335 (25.4\%) & 8 & $0.96(0.32-2.9)$ & 0.916 \\
\hline Sex is male & $1041(78.9 \%)$ & 36 & $1.4(0.44-4.3)$ & 0.462 \\
\hline Age by decade (continuous) & & & $1.7(1.3-2.1)$ & $<.0001$ \\
\hline \multicolumn{5}{|l|}{ SOCIO-DEMOGRAPHIC } \\
\hline 7 or fewer years of education & $124(9.4 \%)$ & 9 & $2.4(0.88-6.5)$ & 0.024 \\
\hline Not married or in stable relationship & $783(59.1 \%)$ & 27 & $1.3(0.56-3.0)$ & 0.425 \\
\hline Unstable accommodation after release & $159(12.0 \%)$ & 10 & $2.2(0.87-5.7)$ & 0.029 \\
\hline Lack of social support (ESSI <= 16) & $116(8.8 \%)$ & 7 & $1.5(0.56-3.9)$ & 0.295 \\
\hline Taken away from family as child & $263(19.9 \%)$ & 12 & $2.0(0.84-4.7)$ & 0.039 \\
\hline Expected money on release $>=\$ 420$ (Median) & $691(52.2 \%)$ & 32 & $2.6(1.04-6.4)$ & 0.007 \\
\hline Any outstanding debts to be settled & $865(65.3 \%)$ & 25 & $1.2(0.50-2.7)$ & 0.653 \\
\hline \multicolumn{5}{|l|}{ CRIMINAL JUSTICE SYSTEM EXPOSURE } \\
\hline Prior adult incarcerations & $885(66.8 \%)$ & 27 & $1.2(0.48-3.1)$ & 0.588 \\
\hline 1 or more extra releases during follow up (time varying) & $670(50.6 \%)$ & 17 & $1.8(0.76-4.3)$ & 0.080 \\
\hline Juvenile detention history & $365(27.6 \%)$ & 14 & $1.9(0.81-4.6)$ & 0.052 \\
\hline Transitional support service accessed & $316(23.9 \%)$ & 11 & $0.92(0.37-2.3)$ & 0.824 \\
\hline \multicolumn{5}{|l|}{ MENTAL HEALTH } \\
\hline Any mental health hospitalisation before prison & $263(19.9 \%)$ & 14 & $2.5(1.1-5.8)$ & 0.006 \\
\hline SF36 Mental Summary score < 31 (Mean-SD) & $202(15.3 \%)$ & 12 & $2.6(1.1-6.1)$ & 0.004 \\
\hline Very high psychological distress (K10 >=30) & $122(9.2 \%)$ & 6 & $1.7(0.53-5.2)$ & 0.255 \\
\hline Ever attempted suicide & $278(21.0 \%)$ & 11 & $1.5(0.62-3.7)$ & 0.230 \\
\hline Possible intellectual disability (HASI $<84.5$ ) & $309(23.3 \%)$ & 8 & $0.86(0.31-2.4)$ & 0.690 \\
\hline Taking CNS medications according to prison medical records & $370(27.9 \%)$ & 14 & $1.2(0.52-2.9)$ & 0.534 \\
\hline Mental illness current & $312(23.6 \%)$ & 9 & $0.98(0.37-2.6)$ & 0.959 \\
\hline \multicolumn{5}{|l|}{ PHYSICAL HEALTH } \\
\hline Taking non-CNS medications recorded in prison medical records & $345(26.1 \%)$ & 18 & $1.3(0.53-3.0)$ & 0.472 \\
\hline Hepatitis C positive & $450(34.0 \%)$ & 20 & $2.4(1.02-5.9)$ & 0.009 \\
\hline SF36 Physical Summary score < 45 (Mean-SD) & $177(13.4 \%)$ & 14 & $2.1(0.83-5.5)$ & 0.039 \\
\hline Overweight waist-height ratio $(\mathrm{M}>58, \mathrm{~F}>54)$ & $379(28.6 \%)$ & 15 & $1.1(0.43-2.7)$ & 0.831 \\
\hline Blood pressure $>=140 / 90$ & $302(22.8 \%)$ & 13 & $0.95(0.39-2.3)$ & 0.893 \\
\hline Diagnosed with asthma ever & $448(33.8 \%)$ & 17 & $1.6(0.68-3.6)$ & 0.165 \\
\hline Diagnosed with heart disease past 12 months & $33(2.5 \%)$ & 5 & $3.1(0.91-10)$ & 0.017 \\
\hline Diagnosed with diabetes ever & $71(5.4 \%)$ & 8 & $2.4(0.69-8.4)$ & 0.070 \\
\hline \multicolumn{5}{|l|}{ SUBSTANCE USE } \\
\hline Possible alcohol dependence (AUDIT >=20) & $372(28.1 \%)$ & 13 & $1.9(0.67-5.4)$ & 0.112 \\
\hline Contact with community drug \& alcohol services before prison & $498(37.6 \%)$ & 18 & $1.9(0.75-4.6)$ & 0.077 \\
\hline High risk cannabis use (ASSIST > 26) & $123(9.3 \%)$ & 1 & $0.36(0.03-4.9)$ & 0.309 \\
\hline High risk methamphetamine use (ASSIST > 26) & $162(12.2 \%)$ & 3 & $0.75(0.16-3.5)$ & 0.623 \\
\hline High risk heroin or other opiate use (ASSIST > 26) & $121(9.1 \%)$ & 7 & $2.8(0.9-8.3)$ & 0.015 \\
\hline Ever injected any drug & $735(55.5 \%)$ & 24 & $2.0(0.76-5.0)$ & 0.066 \\
\hline Injected any drug in the past 12 months & $169(12.8 \%)$ & 8 & $2.4(0.8-7.0)$ & 0.035 \\
\hline Ever overdosed & $303(22.9 \%)$ & 15 & $2.5(1.04-6.1)$ & 0.007 \\
\hline Nicotine dependent (Fagerström score $>=5$ ) & $616(46.5 \%)$ & 23 & $2.1(0.9-4.9)$ & 0.018 \\
\hline
\end{tabular}

${ }^{\mathrm{A}} \mathrm{N}$ is the number of participants exposed. Denominator for percentages is all participants.

${ }^{B}$ The number of deaths within the exposed group.

${ }^{\mathrm{C}}$ AHR is the Adjusted Hazard Ratio. Each row is a separate Cox proportional hazards model, adjusted for age, sex and Indigenous status.

DEach variable listed in the "Standard Covariates" section is used in all of the models. 
Table 4. Multivariable Cox proportional hazards model of all-cause mortality after release from prison ( $\mathrm{N}=1276)$.

\begin{tabular}{lcc}
\hline Parameter & AHR $(99 \% \mathrm{CI})$ & P value \\
\hline Indigenous & $1.1(0.38-3.1)$ & 0.849 \\
Sex is male & $1.5(0.52-4.5)$ & 0.310 \\
Age (in decades) at start of follow up & $1.7(1.3-2.3)$ & $<0.0001$ \\
SF36 Mental health score $<31$ (Mean-SD) & $2.6(1.1-6.1)$ & 0.003 \\
Expected money on release $>=\$ 420$ (Median) & $2.9(1.2-7.1)$ & 0.003 \\
Ever overdosed & $2.5(1.04-6.2)$ & 0.007 \\
\hline
\end{tabular}

This article is protected by copyright. All rights reserved. 


\section{University Library}

\section{- M M N E R VA A gateway to Melbourne's research publications}

Minerva Access is the Institutional Repository of The University of Melbourne

Author/s:

Forsyth, SJ;Carroll, M;Lennox, N;Kinner, SA

Title:

Incidence and risk factors for mortality after release from prison in Australia: a prospective cohort study

Date:

2018-05-01

Citation:

Forsyth, S. J., Carroll, M., Lennox, N. \& Kinner, S. A. (2018). Incidence and risk factors for mortality after release from prison in Australia: a prospective cohort study. ADDICTION, 113 (5), pp.937-945. https://doi.org/10.1111/add.14106.

Persistent Link:

http://hdl.handle.net/11343/294056 